\title{
Arte Parietal de Pompéia: Imagem e cotidiano no mundo romano
}

\author{
Renata Senna Garraffoni
}

Doutora em História pela Universidade Estadual de Campinas (UNICAMP). Professora do Departamento de História da Universidade Federal do Paraná e do Programa de Pós-graduação em História da Universidade Federal do Paraná. Atua no Centro de Pensamento Antigo (CPA) e do Núcleo de Estudos Estratégicos (NEE), ambos da Universidade Estadual de Campinas (UNICAMP). Autora de, entre outros livros, Gladiadores na Roma Antiga: dos combates às paixões cotidianas. São Paulo: Annablume/Fapesp. 2005.resenna93@hotmail.com

\section{ReSUMO}

O artigo apresenta um debate acerca da relevância dos estudos sobre as sociedades antigas, do dialogo entre a Arqueologia e a História e de como os historiadores abordaram seus estudos a respeito de tal tema. Chama a atenção para as muitas intervenções humanas que as cidades antigas sofreram, mas, como é possível por meio da pintura parietal e dos grafites, promover novas interpretações desse passado. Trata das fontes, e destaca os conflitos e contradições da cidade da Campânia promovidos entre grupos rivais. Esta análise é feita por meio do grafite que permitiu construir outras significações do cotidiano apontando a rivalidade para muito além dos grupos comumente estudados. Destaca que a imagem como uma fonte independente é capaz de expressar significados estéticos e simbólicos, ajuda a construir uma interpretação mais complexa do acontecimento estudado.

PALAVRAS-CHAVE: cultura material; grafite; imagem.

\section{Abstract}

The article discusses about the relevance of studies on ancient societies, the dialogue between Archeology and History and how historians conduct their researchers on this theme. It pretends to emphasize human intervention that ancient cities went through, but, how it is possible, analyzing wall painting and graffiti from Pompeii, making new interpretations of the past. Studying the historical source, it detaches the conflicts and contradictions of the city of Campânia promoted by opponent groups. This analysis is based on those graffiti that allowed the construction of other signification of the daily life, showing the rivalry besides those groups usually studied. Emphasizes that image, as an independent historical source, is able to express esthetic and symbolic meanings, and helps us to build an interpretation more complex of the studied event.

KEY WORDS: material culture; graffiti; image. 


\section{Arte Parietal de Pompéia: Imagem e cotidiano no mundo romano}

\section{Introdução}

Caminhar pelas largas avenidas de Roma ou as estreitas vielas das cidades romanas que se espalharam pela Europa, norte da África ou Oriente é sempre uma experiência particular. As ruínas que ali permanecem ainda hoje impressionam pela sua beleza arquitetônica e diversidade de estruturas, proporcionando aos passantes uma percepção fragmentada das cidades antigas.

Em cada momento histórico, estes fragmentos despertaram reações distintas: em alguns períodos as estruturas remanescentes foram reutilizadas na construção de novos edifícios, em outros a preservação foi tema de discussões e lutas para a manutenção da memória dos antepassados ${ }^{1}$. Modernamente, em especial a partir do século XIX, as cidades romanas passaram a serem exploradas pela Arqueologia que, então, nascia como disciplina científica atrelada à História². Neste novo contexto, em que os estados nacionais começavam a se delinear, a idéia na qual um povo se definia por uma língua e um território comum modificou a relação dos europeus com seu passado (Funari e Cavicchioli, 2005).
História e Arqueologia tornaram-se as ciências que definiam métodos e técnicas para ordenar o passado, dar-lhe um sentido para construir as identidades nacionais e as fronteiras dos países que se formavam. Dentro do âmbito do positivismo, da busca pelo passado 'tal como ele realmente aconteceu' nas palavras de Ranke, as primeiras coleções de documentos foram estabelecidos. Durante décadas, a objetividade da Ciência foi fundamental para que os intelectuais definissem as linhas de estudos baseadas em descrições das fontes e, também, separassem os materiais a serem preservados ou descartados. Em geral, preservou-se tudo aquilo que representava a grandiosidade dos romanos, focando as interpretações nas narrativas sobre os grandes homens e em suas conquistas bélicas.

É somente no século XX que estas certezas começam a serem questionadas. A partir das trilhas abertas por Marc Bloch e Lucien Febvre, a chamada Escola dos Annales construiu diversos campos de reflexão sobre a relação dos homens com seu passado. A idéia na qual o presente influencia a interpretação do passado, a percepção que o estudioso é, antes de tudo, um sujeito que interfere na

\footnotetext{
1 Rafael de Urbino, durante o Renascimento italiano, é um dos primeiros a destacar a importância de preservar Roma, a qual chamou de "Cidade Eterna". Sobre esta questão, cf., por exemplo, Teodoro, 1994; Nesseralt 1984; Burns, 1984.

2 É importante destacar que na Europa a Arqueologia surgiu derivada da Filologia e História, preocupada em estudar os vestígios materiais do ocidente, diferente do que ocorreu na América. Para maiores detalhes, cf., por exemplo, Funari e Cavicchioli, 2005.
} 
construção de seu corpus de documentos ou a recusa ao totalitarismo e o imperialismo que produziam interpretações unilaterais das experiências passadas formaram uma postura particular, na qual intelectuais se reuniram em um espírito de busca por interpretações menos lineares da História.

Esta perspectiva foi fundamental para ampliar a percepção do que é um documento histórico, até então entendido como texto, construindo uma História baseada em uma multiplicidade de fontes e de métodos interpretativos calcados na interdisciplinaridade (Le Goff, 2001). É dentro deste contexto que se insere a presente reflexão sobre a arte romana. Considerando que a preservação da arte parietal romana não é somente técnica, mas também estética e política e partindo do pressuposto que o estudo deste tipo de documentação requer um esforço interdisciplinar, ou seja, um diálogo entre História e Arqueologia, gostaria, nesta ocasião, de propor uma discussão sobre o cotidiano romano, suas incertezas e conflitos, tendo em vista a rixa de torcedores ocorrida no anfiteatro de Pompéia no ano de 59 d.C. Para tanto, procurarei fazer uma reflexão sobre a importância de Pompéia para se pensar o mundo romano e, em segundo lugar, discutirei como as imagens presentes nas paredes desta pequena cidade da Campânia romana podem ser consideradas um importante corpus de documento para uma análise do dia a dia das pessoas que circularam por estas ruas antigas.

\section{Escavando Pompéia}

Pompéia, localizada próxima à bacia de Nápolis, no sul da Península itálica, é considerada pelos estudiosos um dos mais importantes sítios arqueológicos do mundo antigo. Muitos acreditam que esta cidade surgiu como um núcleo de agricultores e pescadores oscos na Idade do ferro. Desde o século VIII a.C., Pompéia foi habitada por diferentes povos e, por se localizar próxima ao mar, sempre favoreceu a circulação de pessoas. Assim, oscos, etruscos, gregos, samnitas e romanos circularam por este espaço em diversos períodos tornando a cidade um importante local de comércio e veraneio (Cavicchioli, 2004).

Soterrada pelo vulcão Vesúvio no ano de 79 d.C., Pompéia permaneceu desaparecida até o século XVIII, quando as primeiras incursões foram feitas no local. Somente em 1763 foi confirmado que as ruínas ali presentes eram da cidade de Pompéia, pois foi encontrada uma inscrição dedicada à cidade (Funari, 2003). No entanto, como neste momento a Arqueologia como disciplina ainda não existia, as primeiras escavações foram feitas de forma aleatória, procurando preservar aquilo que a nobreza napolitana do momento acreditava ser mais valioso. Neste contexto, muito se perdeu, em especial pela falta de preservação e constantes saques. Muitos estudiosos de Pompéia, como Varone (1998), apontam a necessidade de se entender este contexto, pois a de retirada de objetos de valor artístico de sítios abandonados e o hábito de colecionar antiguidades era uma prática comum no momento.

Embora durante este período Pompéia tenha sido visitada por pessoas que defendiam o fim destas pilhagens, Etienne (1994) afirma que, somente no século XIX, a cidade passar a ter uma intervenção mais sistemática e menos destruidora. Mesmo que em alguns momentos o interesse tenha sido menor pela escavação, sabemos que Victorio Emmanuele, rei da Itália e seu unificador, aponta Fiorelli como responsável pelo estudo de Pompéia. É somente com Fiorelli que a 
cidade passa a ter uma exploração mais científica e Etienne destaca que foi este homem quem dividiu a cidade em regiões e quarteirões (insulae), sistema de demarcação utilizado até hoje pelos arqueólogos, além de ter escavado o prostíbulo e outras regiões da cidade.

Se Fiorelli é um dos mais importantes arqueólogos do século XIX, responsável por uma escavação menos destrutiva, Amadeo Maiuri é o superintendente mais polêmico do século XX. Mauiri ocupou o cargo entre 1924 e 1961 desenvolvendo seus trabalhos a partir de financiamentos do governo fascista de Mussolini. Embora boa parte de Pompéia tenha sido escavada neste período, estudiosos criticam as restaurações inadequadas por ele propostas que mais indicavam uma percepção fascista do que era o Império do que uma estética romana propriamente dita. Suas restaurações visavam à propaganda do regime fascista, tornando Pompéia o orgulho nacional, substrato para as idéias de superioridade italiana moderna, já que estes descendiam de um povo conquistador. Cavicchioli (2004) ressalta ainda que, durante direção de Maiuri, muitos objetos foram retirados de seus contextos originais, em especial os que feriam a conduta de moralidade fascista como as pinturas e objetos com representações sexuais ou fálicas, descritas na época como pornográficas. Atitudes como esta restringiam o acesso ao material escavado em Pompéia, bem como alteraram os contextos nas quais foram encontrados.

Estas considerações acerca da escavação de Pompéia, embora tenham sido apresentadas de maneira sucinta, permite uma reflexão particular: o que hoje consideramos o sítio arqueológico de Pompéia é um local que passou por diversas intervenções sejam elas naturais, como a erupção do Vesúvio que preservou alguns de seus aspectos, mas destruiu outros e as escavações do local. Tais escavações foram permeadas por saques, atravessadas pela estética napolitana do século XVIII, pelas primeiras escavações científicas, pelo fascismo de Mussolini e pela destruição dos bombardeios durante a II Guerra. Assim, o que hoje se preservou não deve ser entendido como uma ilustração direta do que era uma pequena cidade administrada pelos romanos no século I d.C., mas um sítio arqueológico que sofreu alterações naturais e humanas. Neste sentido, mais do que estudarmos o cotidiano de Pompéia como um reflexo do dia a dia romano, a idéia seria pensar este local na sua especificidade, nas suas tensões e conflitos, entendendo o mundo romano não como uma sociedade homogenia, mas formada a partir de uma pluralidade de sujeitos. Esta perspectiva possibilita o questionamento de parâmetros culturais absolutos para os romanos que foram estabelecidos pela historiografia ao longo do século $X X$ e foca na experiência de vida, enfatizando sua fluidez e contradições ${ }^{3}$.

Se por um lado as intervenções alteraram a estrutura da cidade, por outro é importante ressaltar que nem sempre Pompéia esteve no centro das interpretações dos estudiosos. Durante muito tempo foi considerada um mero depósito de evidências e muitos classicistas recorriam à cidade para comprovar o que tinham lido nos textos romanos. Com o desenvolvimento da Arqueologia, em especial de vertentes de pensamento que questionaram a idéia na

\footnotetext{
${ }^{3}$ Sobre a importância da História do cotidiano para desmistificar interpretações absolutas da sociedade, cf., por exemplo, Dias 1998.
} 
qual a Arqueologia servia para escavar dados para suprir a História, a relação entre ambas disciplinas se alterou ${ }^{4}$. Assim, muitos estudiosos têm trabalhado em uma perspectiva dialógica, ou seja, ao invés de utilizarem a cultura material como ilustração do texto, cada artefato passou a ser interpretado em seu contexto, ora preenchendo lacunas da documentação escrita, ora conflitando com ela.

A partir do exposto, ressalto que minha aproximação de Pompéia e seu cotidiano é feita tendo por base um viés que considera as intervenções no sítio e seus limites e visa uma interpretação da cultura material a partir de suas particularidades, pois como afirma Dommelen (1997), a Arqueologia permite o estudo de caso redefinindo a situação do local em que os artefatos foram encontrados. Dentro do universo cultural de Pompéia e sua diversidade, enfocarei, nesta ocasião, as paredes da cidade, pois nelas é possível notar expressões imagéticas e epigráficas das mais variadas espécies: pinturas de refinados estilos, grafites que tratam desde ofensas pessoais a poesias amorais, passando por ironias e charadas, além de propagandas eleitorais ou dos espetáculos públicos.

Como a idéia é pensar os conflitos e contradições desta cidade da Campânia, gostaria de me deter a um estudo de caso específico: a rixa que ocorreu no anfiteatro. Há diferentes tipos de registros sobre este evento. O mais conhecido é o relato de Tácito, nos Anais (XIV, 17) e a arte parietal, seja a pintura como os grafites, é pouco valorizada, pois tradicionalmente é empregada para ilustrar a descrição do historiador romano. No entanto, uma leitura cuidadosa das imagens destas paredes em seu contexto original e desobrigada de comprovar o relato de Tácito pode fornecer indícios para pensarmos as formas de identidade nesta cidade. Para tanto, seria interessante, antes de interpretarmos as evidências, tecermos alguns comentários sobre a arte parietal romana.

Arte parietal romana: as pinturas e os grafites

As paredes da cidade de Pompéia, que sobreviveram à erupção do Vesúvio, tornaram-se um importante corpus de pinturas e inscrições acerca do mundo romano. Seguramente, Pompéia possui apenas uma fração dos estilos de arte parietal que se desenvolveram no mundo romano, mas foi a partir dela que foram estabelecidas as cronologias e as tipologias ainda no século XIX. Como basearei minha análise em duas categorias imagéticas distintas, a pintura e os grafites, é interessante pensar o contexto de estudo de cada uma delas. Iniciemos pelas pinturas.

Funari e Cavicchioli (2005) afirmam que embora tenham existido pinturas portáteis, em geral feitas em painéis de madeira, a partir do século I a.C. as pinturas de parede passam a fazer parte da estética artística romana. Os autores destacam, também, que a técnica pictórica mais comum era o afresco. A parede era preparada com uma capa de cal e pó de mármore e os extratos de preparação poderiam conter até sete camadas, em uma tentativa de refinar a parede e, ao mesmo tempo, evitar umidade e infiltrações. Em geral a pintura era feita antes da última camada, desenhada por um pintor mais experiente que delineava a decoração e o trabalho era completado por seus ajudantes. Tais pinturas, segundo Funari e Cavicchioli, poderiam ser realizadas nas paredes internas ou externas

\footnotetext{
${ }^{4}$ Sobre o questionamento da idéia da Arqueologia como "serva" da História, cf. Funari et Zarankin, 2001; Funari, Jones et Hall, 1999; Storey, 1999.
} 
da casa, sendo que estas últimas recebiam menos cuidados e foram consideradas, pelos estudiosos modernos, com menos valor artístico.

As pinturas variavam de acordo com o contexto, isto é, dependendo do cômodo, da luminosidade, dos móveis e do efeito que se queria proporcionar, tornando-se, assim, uma arte complexa, organizada e planejada. Dada a diversidade, Ling (1991) afirma que as pinturas mais elaboradas foram as mais estudadas por historiadores da Arte, sendo que o primeiro a estabelecer as diferenças e os tipos de estilo foi Augusto Mau, em 1882. Apesar das críticas e complementos posteriores, a divisão em quatro estilos proposta por Mau segue sendo utilizada até hoje. De maneira resumida, é possível afirmar que o critério empregado por Mau foi cronológico estabelecendo a seguinte evolução: Estilo I "estrutural ou mármore fingido" (do séc. III a.C. até séc. I a.C.) - relevo criava a impressão de placas de mármore; Estilo II "estilo arquitetônico" (séc. I a.C.) perspectivas falsas, colunas e outros tipos de imitação arquitetônica; Estilo III "estilo ornamental" (final do séc. I a.C. até início do séc. I d.C.) - ornamentação rica e delicada, muitos motivos egípcios; Estilo IV "estilo fantástico" (início do século I d.C.) - estilo rebuscado e forte presença de elementos da mitologia 5 .

No que diz respeito à evolução e transformações deste estilo há um grande debate. O próprio Mau afirmou que as transformações eram algo externo a Pompéia, enquanto que Little (1945), já nos anos de 1940, discordava desta postura, argumentando que, embora haja uma influência helênica, os estilos de Pompéia teriam se modificado a partir dos gostos locais, com a inclusão de elementos teatrais e satíricos que expressariam as escolhas da elite pompeiana. Além de um debate interno sobre estes estilos e suas modificações, há também uma discussão acerca de quais pinturas poderiam ser enquadradas nestes estilos. Há uma grande quantidade de pinturas de jardins e peristilos, por exemplo, que não fazem parte destes estilos e foram denominadas de populares. Entre estes pinturas estão as cenas cotidianas, como a rixa no anfiteatro ou as chamadas pinturas eróticas. Tal diferenciação indica que os critérios de catalogação não são neutros, são construídos a partir da perspectivas dos estudiosos e, como afirmam Funari e Cavicchioli, muitas vezes, expressam quais os aspectos da cultura romana se pretendem preservar.

Se por um lado os sistemas de pintura foram catalogados e têm sido sistematicamente estudados, por outro, os grafites de parede ainda são pouco conhecidos. Desde o século XIX, todas estas inscrições de cunho popular são catalogadas no CIL, Corpus Inscriptionum Latinarum, mas foram poucos os estudiosos que se dedicaram a interpretá-las, se compararmos com as pesquisas acerca das pinturas dos IV estilos. Segundo Feitosa (2005: 59-61), até há pouco tempo, o volume IV, destinado a região vesuviana, contava com quase onze mil grafites. A grande maioria deles é copiada conforme os originais, mas há muitos que são anotados a partir da pontuação e interpretação do paleógrafo que o transcreveu. Esta ressalva é muito importante, pois temos que estar conscientes que a leitura que fazemos destes grafites pode ser influenciada pela anotação de outros.

${ }^{5}$ Para maiores detalhes sobre os estilos, cf. Funari e Cavicchioli, 2005: 115-116. 
Mas o que seriam estes grafites? Diferentemente das inscrições oficiais que eram pintadas para serem vistas a longa distância, os grafites eram pequenos e precisavam ser vistos de perto. Sulcados nas paredes com um estilete (em latim graphium), os grafites produziam uma relação distinta com o público: eram pessoais e o leitor tinha que se aproximar da parede para poder enxergá-los.

Em geral eram escritos em ambientes fechados, embora muitos sejam encontrados nas paredes externas das casas pompeianas. Impulsivo, imediato e espontâneo o grafite é um registro singular que marca um momento específico ou uma necessidade pessoal de deixar registrado uma insatisfação, uma piada ou uma declaração de amor tornando-se, portanto, uma fonte de inestimável valor para o estudo dos anseios e paixões cotidianas a partir de uma perspectiva coletiva ${ }^{6}$. Seus tipos são variados alguns são simples inscrições, outros são acompanhados de desenhos e, por isso, devem ser analisados em conjunto.

A particularidade deste tipo de registro, além de sua espontaneidade, é a possibilidade de adentrar a estética das camadas populares, tão pouco documentada. Se as pinturas são feitas por meio do contrato de pintores, os grafites são cunhados de próprio punho por aquele que deseja expressar sua mensagem. Neste sentido, analisar este conjunto de documentação sobre a rixa no anfiteatro nos propicia uma leitura da perspectiva local, no calor da hora, um tipo de registro diferente do proporcionado por Tácito, escrito a posteriori com claras implicações políticas ${ }^{7}$. Observemos, então, estes registros.

\section{A rixa no anfiteatro de Pompéia (59 d.C.)}

Tácito, no relato mencionado, aponta os moradores de Nucéria e Pompéia como os principais atuantes no confronto ocorrido no anfiteatro de Pompéia, em 59 d.C. Pesquisadores modernos sugerem que a desavença ocorrida durante o combate de gladiadores está relacionada à reorganização dos limites territoriais: o estabelecimento da nova colônia neroniana em Nucéria em 57 d.C. acabou por agravar uma situação tensa de longa data (Castrén, 1983: 108-113).

Pompéia fazia parte de uma confederação junto com Nucéria, extinta por volta de 216 a.C., na qual os samnitas constituíam o grupo predominante. Em finais do século I a.C. após guerras e conflitos locais, Nucéria se encontrava restabelecida e lutou ao lado dos romanos quando estes tomaram, definitivamente, a região ${ }^{8}$. De acordo com Pesando (2001), os distintos processos de formação da cidade de Pompéia desempenhariam um papel importante para a compreensão do conflito em questão. Antigos habitantes de períodos anteriores à chegada dos romanos e os novos que vieram após a conquista circulavam pelas ruas de Pompéia com distintos interesses políticos e econômicos.

Embora o estopim do confronto tenha sido a reunião para presenciar um espetáculo de gladiador, o texto de Tácito não deixa claro o local em que o confronto ocorreu. Por outro lado, a pintura de parede, que atualmente se encontra no Museu Arqueológico Nacional, situado em Nápoles, sul da Itália, centraliza o conflito no anfiteatro (figura 1). Observemos a pintura:

\footnotetext{
${ }^{6}$ De acordo com Funari: "o grafismo popular diferenciava-se, desde o início, pelo seu caráter coletivo: não se trata de refletir um mundo distante, como no interior das mansões, mas de retratar, nas paredes externas, a vida concreta, as paixões populares em sua imediaticidade." (Funari, 1989: 39). Sobre a questão da imediaticidade do grafite cf, também, Barbet, 1987.

7 Para esta ocasião me deterei a análise da pintura e dos grafites. Mas para uma análise em conjunto com o texto de Tácito, cf. Garraffoni, 2005: 136-141.

${ }^{8}$ Sobre os diversos conflitos na região até a chegada dos romanos, cf. Bomgardner, 2002: 50-53.
} 


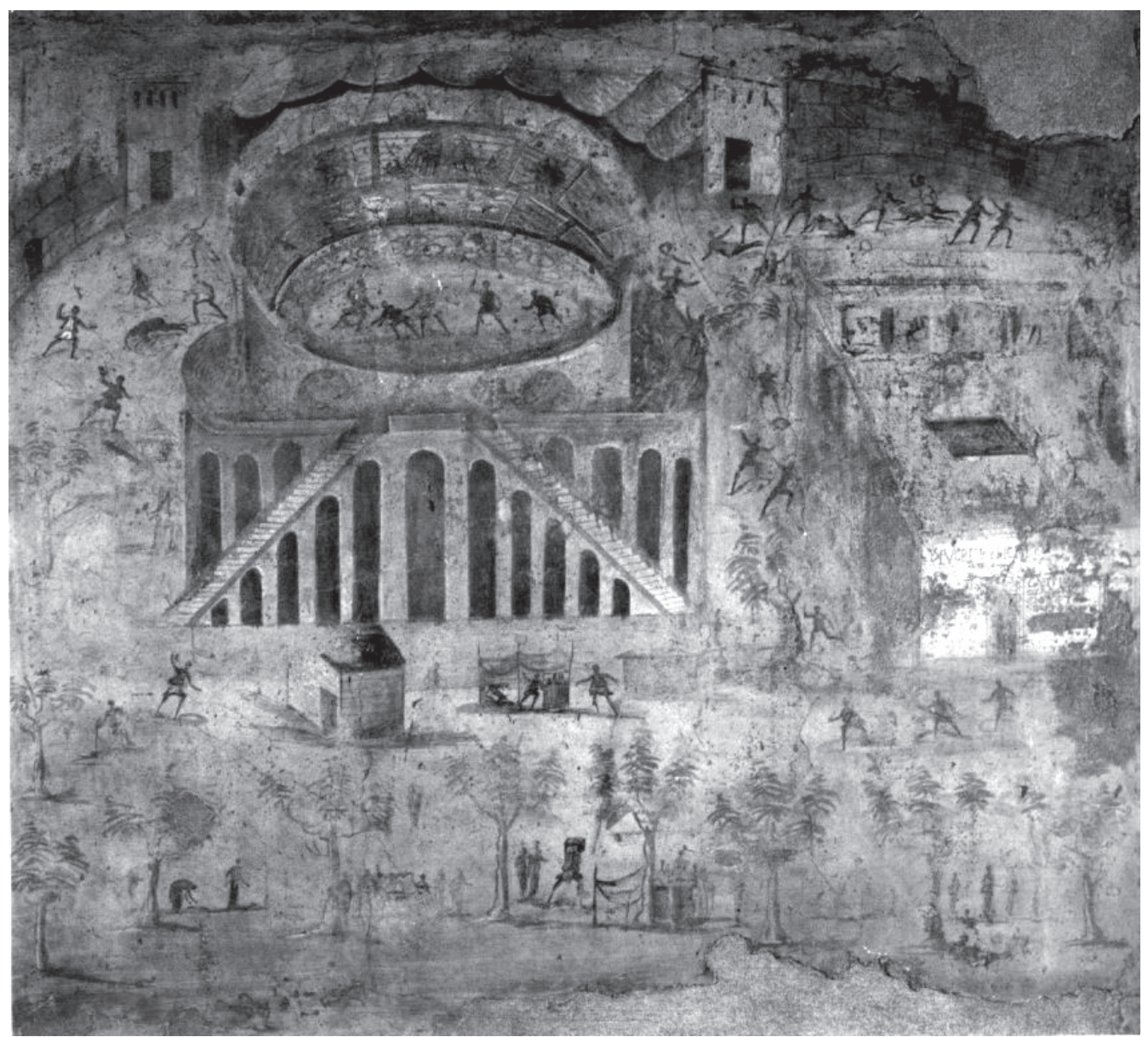

Figura 1. Pintura parietal pompeiana da casa de Actius Anicetus - reg. I, ins. 3, 23 (in: LA REGINA, 2001: 333).

Originalmente, este afresco fazia parte da decoração do peristilo da casa de Actius Anicetus (reg. I, ins. 3, 23). Tradicionalmente, o peristilo de uma casa romana é aberto, rodeado de colunas e comporta um jardim, características do espaço em que a pintura foi encontrada. Sendo assim, esta pintura, datada de época nero-flaviana, se destaca por sua exterioridade e exposição ao tempo, em um local que ficava à vista de todos aqueles que se movimentavam pela casa.

Por retratar cenas de episódios cotidianos, tal pintura não se encontra na tipologia proposta por Mau no século XIX, como comentei nas linhas anteriores, mas é estudada como sendo de cunho "popular". Zevi (1991), afirma que as "pinturas populares" são representações figurativas que trazem cenas do dia a dia como as procissões religiosas a uma divindade, cenas de tavernas, lupanares, de gladiadores, caçadas ou espetáculos nos anfiteatros, por exemplo. A grande maioria destas pinturas se encontra, atualmente, no Museu de Nápoles, pois é somente no início do século $X X$ que se estabeleceu um programa de preservação e restauro.

Zevi aponta como suas principais características a indiferença com a questão espacial e dimensional da cena e o fato de ser uma pintura de ocasião, de exposição e, 
por isso, quase sempre localizada em paredes externas das casas. Além de terem pouca duração (eram bastante econômicas), tais pinturas retratam cenas de caráter histórico e local, sendo seu grande expoente a representação da briga no anfiteatro.

De acordo com Zevi, o protagonista da cena em questão é o próprio anfiteatro. De fato, se olharmos atentamente a representação percebe-se que um dos aspectos centrais de sua composição é a estrutura arquitetônica. O pintor preocupouse em retratar o anfiteatro com o toldo de proteção solar quase no centro, mas não esqueceu da muralha, da palestra e de uma pequena construção de pedra próxima a escadaria. A posição em que colocou o anfiteatro e o seu tamanho, muito maior que os outros elementos da cena, nos instiga a pensar que pretendia destacar o epicentro do conflito.

O próprio recurso empregado pelo pintor de contrapor a escadaria, em forma de triângulo, ao centro da arena, em forma oval, dirige o olhar do passante às cenas de combate na arena e nas arquibancadas, ponto este que, segundo Zevi, sairiam as principais linhas de fuga da pintura. Muito se discutiu sobre o fato da escadaria representada não corresponder às proporções originais. Realmente, ao comparar com as escadas do anfiteatro é possível perceber que há um número menor de arcadas que a representada na pintura. No entanto, considerando a afirmação de Zevi na qual em tais pinturas não haveria uma preocupação exata com as dimensões dos edifícios, acredito que o pintor não fez uma reprodução do anfiteatro "tal como ele realmente era" mas recriou-o ao seu estilo, de uma maneira que nos permite ver seu interior e exterior.
Esta particularidade nos parece muito significativa, pois possibilita uma dinâmica específica da cena: as pessoas estariam em combate no interior e ao redor do anfiteatro. Se observarmos com atenção, a maior quantidade de pessoas está na parte de cima da pintura, isto é mais próxima do anfiteatro, enquanto que sua presença mais abaixo é esporádica predominando a vegetação e um pequeno comércio de ambulantes por motivo do munus. Os corpos das que estão mais próximas do anfiteatro estão inclinados e os movimentos são semelhantes, transmitindo uma idéia de correria e luta corporal, enquanto que as outras figuras abaixo ou estão paradas olhando o episódio ou recolhendo seus pertences nas barraquinhas.

Tudo indica, em minha opinião, que o pintor teria pintado na parede do peristilo da casa de Actius Anicetus um momento específico do conflito entre pompeianos e nucerinos, deixando em sua perspectiva do evento representações de aspectos que não aparecem no texto de Tácito, como o comércio ocasional de uma cidade da Campânia. Além disso, a própria necessidade de retratar o episódio em um local da casa que poderia ser visto com freqüência por seus moradores e visitantes também nos parece relevante, pois esta seria uma maneira de manter viva a lembrança do conflito.

Se a pintura foca o anfiteatro produzindo uma referência mais explícita aos combates de gladiadores que o texto de Tácito, alguns grafites o fazem de uma maneira mais clara ainda. Para esta análise, selecionei quatro grafites, um com expressões e acompanhado de desenho e outros três constituídos apenas por palavras. Observemos o primeiro deles (figura 2). 

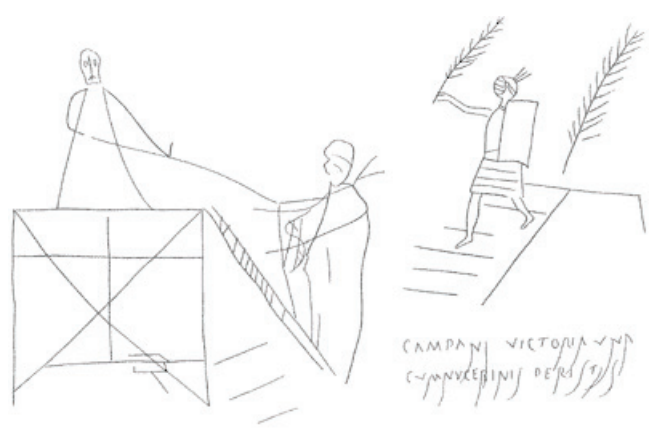

Figura 2. Grafite parietal sobre a rixa de torcedores em Pompéia - CIL IV, 1293 (in: Langner, 2001, imagem n 1138 de seu catálogo).

Este grafite se encontra na parede externa da casa Dioscuri (reg. VI, ins. 9, 6) localizada na rua Mercúrio. Esta casa possui duas entradas e uma ampla fachada. Escavada entre 1828-1829 e conhecida pela riqueza de pinturas do IV estilo em seu interior (Baldassare, 1993), esta casa se situa nas imediações do forum de Pompéia, o que nos faz imaginar uma região com grande circulação de pessoas das mais variadas etnias e condições sociais. Com um grande muro revestido de estuco branco para imitar uma parede de bloco de mármore, característica das pinturas de época republicana, a parede externa da casa foi alvo dos "grafiteiros" romanos nesta movimentada região da cidade.

No caso do grafite em questão, percebese, de imediato, que é composto por um conjunto de figuras e um texto em latim. A figura situada à esquerda representa a subida de um homem ao podium e à direita, acima da inscrição, um gladiador vestido com elmo e escudo segurando uma palma, símbolo do vencedor. Os dois desenhos são referências diretas a um momento específico dos combates de gladiadores: a premiação do vencedor. Podium, palma e a figura de gladiadores sobre uma inscrição que faz referência à derrota dos nucerinos. Observemos a inscrição:

Campani uictoria una cum nucerinis peristis

(CIL IV, 1293)

[Campanos, em uma única vitória, vocês pereceram com os nucerinos]

Segundo Moeller (1970), o termo campani causou controvérsias entre os estudiosos. Há autores que consideram campani um grupo aristocrático samnita (antigos moradores de Pompéia), idéia que questiona. Para o autor, o texto de Tácito é fundamental para rechaçar esta suposição. Analisando termos empregados por Tácito como oppidana lasciuia ou ualidore pompeianorum plebe, Moeller afirma que os participantes do conflito seriam membros das camadas populares e descarta a participação de grupos aristocráticos. Sua postura visa ressaltar que fãs dos combates ou do circo e teatro poderiam participar ativamente da vida política da cidade, inclusive em momentos de conflitos como este de 59 d.C.

Embora o grafite sozinho não traz elementos suficientes para precisarmos quem seriam os campanos, ele indica a percepção de diferentes grupos em conflito. Enquanto Tácito menciona uma luta entre pompeianos e nucerinos, o grafite, localizado perto de um local muito movimento, traz o registro que ressalta que, além dos nucerinos, os campanos também saíram derrotados, trazendo um novo elemento para o conflito. Ao aliar este a um segundo grafite, encontrado no lado ocidental do lupanarnotase o posicionamento de outros grupos rivais: 
Puteolanis feliciter omnibus nucherinis felicia et uncu(m) Pompeianis

etecsanis

(CIL IV, 2183)

[Para os puteolanos "boa sorte", para os nucerinos coisas boas e gancho para os pompeianos e pitecusanos.]

Este grafite apresenta uma oposição entre dois grupos: puteolanos e nucerinos/ pompeianos e pitecusanos. De acordo com as anotações do CIL o grafite foi escrito em dois momentos: em primeiro lugar teria sido escrita a linha de "boa sorte" aos puteolanos e nucerinos e, depois, a parte seguinte da frase teria sido escrita por outra pessoa, pois as letras são distintas. Neste sentido, a expressão et uncu $(m)$ pompeianis petecsanis teria sido acrescentada por um partidário dos primeiros. Uncus é um substantivo que pode significar qualquer tipo de gancho, mas também um em específico utilizado para arrastar cadáveres, o que indica um desejo de liquidar e humilhar os pompeianos e pitecusanos.

As desavenças entre os grupos podem ser encontradas em um outro grafite situado na estrada de Mercúrio. Em uma das paredes lê-se:

Nucerinis infelicia Mentul... (CIL IV, 1329)

[Para os nucerinos desgraça Caralho...]

Assim como o caso do grafite anterior, este também é escrito em dois momentos. Em primeiro lugar aparece o desejo de desgraça e infelicidade aos nucerinos, uma provocação, um xingamento. Segundo Mommsen, mentul... foi acrescentado por outra mão, posteriormente, o que nos faz pensar que um nucerino ou simpatizante da cidade usou o termo mentula, ae (falo, pênis) em um sentido apotropaico, isto é, para afastar o azar que uma frase como esta poderia representar.

Tanto este grafite como o do prostíbulo me pareceu interessante na medida em que apresenta uma dinâmica particular neste tipo de escrita: nos dois casos a ofensa ou saudação foi complementada por terceiros, indicando que este tipo de comunicação fazia parte do cotidiano daqueles que passavam pelas ruas e edifícios de Pompéia. Mesmo que ambos não mencionem a rixa de torcedores, tais grafites são indícios de que as desavenças entre nucerinos, pompeianos e moradores de outras cidades vizinhas eram parte do dia a dia da cidade e de conhecimento da população local. Sintomático, portanto, que tais provocações estivessem em locais de grande circulação de pessoas, em muros próximos ao forum e num prostíbulo, bem distantes do anfiteatro, local onde se deu o espetáculo em que eclodiu o conflito armado.

Tanto a pintura como os grafites nos oferecem relatos particulares de alguns dos conflitos pompeianos e muito distintos do de Tácito. As questões locais emergem em detalhes enquanto que nos Anais são aglutinados pelo termo oppidana lasciuia. Por meio das fontes materiais o anfiteatro assume um papel mais central, assim como as disputas locais: nucerinos, puteolanos, pompeianos, pitecusanos, campanos são mencionados em distintos ambientes da cidade ampliando nossa noção dos grupos rivais que poderiam estar presentes na rixa. Assim, mais do que ilustrar o relato de Tácito, a pintura e os grafites apresentam uma interação mais popular do confronto e não somente uma briga dirigida pelo ex-senador, como propõem estudiosos que se restringem ao relato dos Anais.

Neste sentido, é possível afirmar que a pintura e os grafites são fontes que nos levam 
a perceber que os espectadores dos combates não eram passivos, mas formavam grupos que poderiam tomar diferentes partidos nas disputas. Além disso, tais fontes também indicam que as estruturas de segregação, como as entradas separadas para as camadas sociais dos anfiteatros, não impediram a reorganização das pessoas e a explosão do conflito latente. O exemplo de Pompéia, portanto, torna-se significativo, pois apresenta pessoas que mesmo compartilhando um gosto em comum pelos combates, não tinham uma atitude apática como muitos estudiosos argumentam: a diversidade de opiniões entre os espectadores emerge com força nestas fontes e poderia, como em muitos outros casos, acirrar conflitos.

\section{Considerações finais}

A análise da rixa a partir da cultura material, ou seja, da pintura parietal e dos grafites, proporciona um olhar particular sobre o evento. Embora tradicionalmente o relato de Tácito tenha sido considerado a principal fonte para compreender o episódio, um estudo interdisciplinar, que considere a imagem como uma fonte independente e capaz de expressar significados estéticos e simbólicos, ajuda a construir uma interpretação mais complexa deste acontecimento. A partir do registro imagético é possível entender o evento em uma perspectiva local, conhecer os diferentes grupos envolvidos bem como refletir sobre a sua abrangência no momento, pois o fato de se pintar o episódio e manifestar os descontentamentos em grafites indica uma reorganização das identidades locais que nem sempre foram pacíficas.

Se por um lado a rixa de torcedores em Pompéia é um acontecimento único registrado na Campânia, por outro ela indica, também, os conflitos que permeiam a presença romana em suas colônias. Ter em mente este conflito e suas diferentes representações significa estar atento às diferentes possibilidades de ação humana, em especial em locais públicos que reúnem muitas pessoas. Os anfiteatros congregam experiências humanas e percepções de espaço que se modificam de acordo com a região em que foram construídos, causando espanto, admiração ou potencializando conflitos entre aqueles que os freqüentavam.

\section{Agradecimentos}

Gostaria de agradecer a Angelita Marques Visalli (UEL - Universidade Estadual de Londrina) e a comissão organizadora do I Encontro Nacional de Estudos da Imagem pelo convite para participar do Evento organizado pelo LEDI. Gostaria de mencionar, também, meus agradecimentos aos colegas Marina Régis Cavicchioli, Lourdes Feitosa e Pedro Paulo Funari pelo diálogo em todos estes anos, além do apoio institucional da UFPR (Universidade Federal do Paraná) e do NEE (Núcleo de Estudos Estratégicos da Unicamp).

\section{Bibliografia citada}

\section{Fontes:}

Tácito (1986), Annals (trad. J. Jackson), Londres, Harvard University Press, Coleção Loeb.

\section{Bibliografia Moderna:}

BALDASSARE, I. et alli, 1993. Pompei - Pitture e mosaici - Enciclopedia dell'arte antica classica e Orientale, Roma.

BARBET, A., 1987. "La representation des gladiateurs dans la peinture murale romaine", in: Les Gladiateurs: Lattes, Toulouse, pp. 69-74.

BOMGARDNER, D.L., 2002. The story of the Roman amphitheater, Routledge, Londres. 
BURNS, H., 1984. "Raffaello e 'quell'antiqua architectura'", in: Raffaello Architetto - C.L.Frommel et alli (org.), Ellecta Editrice, Milão, pp. 381-404.

CASTRÉN, P., 1983. Ordo populesque pompeianus - Polity and society in Roman Pompeii, Bardi Editore, Roma.

CAVICCHIOLI, M.R., 2004. As Representações da Sexualidade na Iconografia Pompeiana, dissertação de mestrado defendida na Unicamp.

DIAS, M.O.S., 1998. "Hermenêutica do quotidiano na historiografia contemporânea", in: Projeto História, PUC-SP, S.P., no 17, nov. pp. 223-258.

DOMMELEN, P. van, 1997. "Colonial constructs: colonialism and Archaeology in the Mediterranean", in: World Achaeology, vol. 28 (3): 305-323

ETIENNE, R., 1994. Pompeii - The Day a City Died, Thames and Hudson Ltd, Nova York.

FEITOSA, L.C., 2005. Amor e sexualidade: o masculino e o feminino em grafites de Pompéia, Annablume/Fapesp.

FUNARI, P.P.A. 1989. La cultura popular en la Antigüedad Clásica, Editorial Gráficas Sol, Espanha.

FUNARI, P.P.A., JONES, S. et HALL, M. 1999. Historical Archaeology - Back from the Edge, London: Routledge.

FUNARI, P.P.A. et ZARANKIN, A. 2001. "Abordajes arqueológicos de la vivienda doméstica en Pompeya: algunas consideraciones", in: Gerión,19, 493-512.

FUNARI, P.P.A., 2003. A vida quotidiana na Roma Antiga, Annablume, S.P.

FUNARI, P.P.A et CAVICCHIOLI, M., 2005. "Arte parietal romana e diversidade", in: Revisão Historiográfica - o estado da questão (Miyoshi, A.G et alli - orgs), Unicamp/IFCH, pp.111-124.

GARRAFFONI, R.S, 2005. Gladiadores na Roma Antiga: dos combates às paixões cotidianas, Editora Annablume/ FAPESP, S.P.
LA REGINA, A. 2001. Sangue e arena, Electa, Roma.

LANGNER, M., 2001. Antike Graffitizeichnungen - Motive, Gestaltung und Bedeutung, Wiesbaden.

LE GOFF, J., 2001. "A História Nova", in: $A$ História Nova (Le Goff, J. - org), Martins Fontes, S.P., pp.29-30.

LING, R. 1991. Roman Painting, Cambridge University Press, Cambridge.

LITTLE, A.M.G., 1945. "The formation of a Roman Style in wall painting", in: American Journal of Archaeology, vol. 49 (2), pp. 134-142.

MOELLER, W.O., 1970. "The riot of AD 59 at Pompeii", in: Historia - Zeitschrift für Alte Geschichte, 19, pp. 84-95.

NESSELRATH, A., 1984. "Raffaello e lo studio dell'antico nel Renascimento", in: Raffaello Architetto - C.L.Frommel et alli (org.), Ellecta Editrice, Milão, pp. 405-408.

PESANDO, F., 2001. "Gladiatori a Pompei", Sangue e arena (LA REGINA, A. - org.), Electa, Milão, pp. 175-197.

STOREY, G.R., 1999. "Archaeology and Roman Society: Integrating Textual and Archaeological data", in: Journal Of Archaeological Research, vol. 7, no 3, pp.203-248.

TEODORO, F.P., 1994. di, Raffaello, Baldassar Castiglione e la Lettera a Leone $X$, Nuova Alfa Editoriale, Bolonha.

VARONE, A., 1998. "Gli scavi dal 1748 al 1815", in: D'Ambrosio, A. (org) Alla scoperta di Pompei, Milão, Electra.

ZEVI, F., 1991. "L'arte 'popolare'", in: La pittura di Pompei - Testimonianze dell'arte romana nella zona repolta dal Vesuvio nel 79 d. C. (Francisci, A. et alli - org.), Jaca Book, Milão, pp. 267-273. 